\title{
A NOVEL INTERMEDIATE LINE REGULATOR SUITABLE FOR USE AS A CURRENT SOURCE CONVERTER
}

\author{
F. A. Saafan, D. M. Yehia, M. E. Abdel-Karim, M. A. Elkhazendar \\ Electrical Engineering Department, Faculty of Engineering, \\ Tanta University, Tanta, Egypt
}

\begin{abstract}
In this paper, a novel intermediate line regulator suitable for use as a current source converter is proposed. The operation principle of this converter is mainly based on switched series inductor and switched shunt capacitor. Thus, two semiconductor devices only are used for single-phase systems and six semiconductor devices for three-phase systems. This reduces switching losses and increases the efficiency compared to that of previous topologies. The control strategy is built via pulse width modulation technique accompanied by the control method used. In this study, two different control methods, conventional PI and fuzzy logic, are tested and compared to select the preferable one. The simulation results of the proposed converter are presented based on MATLAB/SIMULINK tools. Also, the results of the three-phase arrangement are shown with the simulated waveforms. In order to validate the converter operation, a laboratory prototype based on TMS320C31 digital signal processor has been designed and constructed. Experimental results for different cases are presented.

محو لات القدرة الإستاتيكية تلعب دور حيوي وهام في نظم القوى الكهربية الخديثة حيث أنها المسنولة عن إمداد

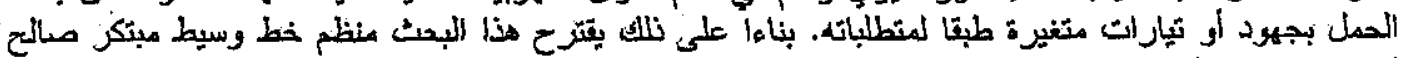

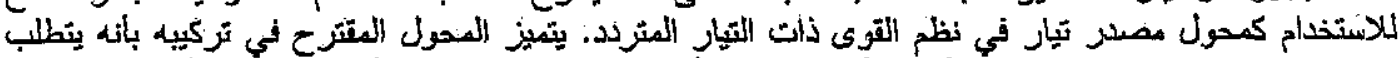

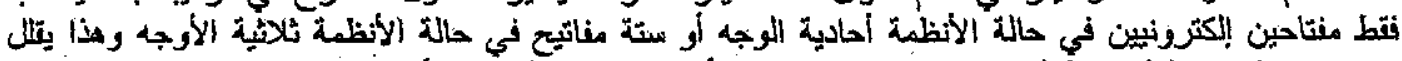

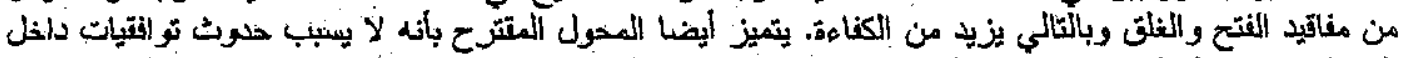

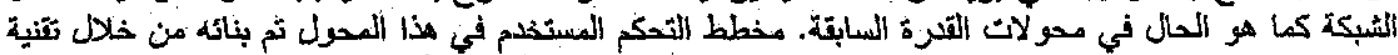

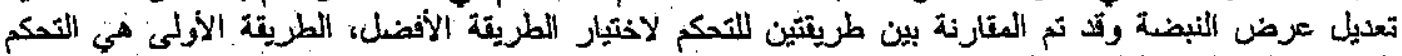

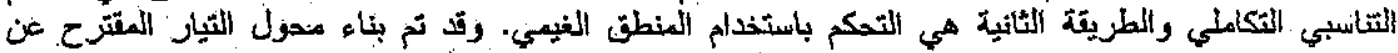

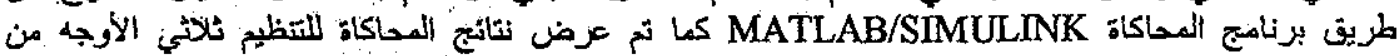

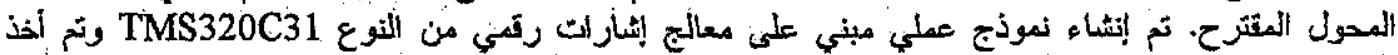

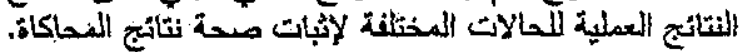

Keywords: Intermediate Line Regulator, Current Source Converter, Digital Signal Processing, Fuzzy Logic Based Control.

\section{INTRODUCTION}

Electrical energy is primarily distributed as ac voltage at constant amplitude and frequency. However, most of the electrical loads may demand different requirements. For instance, in a modern adjustable speed drive, induction machines require a variable ac voltage and variable frequency supply as the speed requirements vary. Therefore, to interface a load to the ac mains, a power conversion system is required. Today, electrical power conversion is basically achieved by means of static power converters. These static power converters can be used in many applications such as motor drives, power supplies, and active power filters.
There are different topologies for ac/ac energy transfer. The voltage source converter (VSC) is the most common power converter today, extensively used in ac drive systems, ac uninterruptible power supplies, and active power filters [1]. It is simple, robust, and easy to control. Wide ranges of the frequency and magnitude of fundamental output voltage are attainable. However, VSCs, typically based on fast-switching, are not free of certain drawbacks as evidenced by a slate of publications.. These include substantial switching losses, radiated electromagnetic interference, high dv/dt in the output voltage, and no current limiting capability in case of failure. 
As a partial remedy, the current source converter (CSC) was used. The power circuit of the CSC is simpler and more robust than that of the VSC as a result of the absence of freewheeling diodes. Besides $\mathrm{CSC}$ provides an inherent protection from shortcircuit currents due to the large dc-link inductance and current control in the rectifier and also provides the advantages of low dv/dt in the output voltage due to the output filter capacitor. However, CSCs have their weaknesses too, such as the increased size and cost, reduced efficiency resulting from higher conduction losses, greater complexity of the control algorithm, and susceptibility to resonance between the output capacitors and load inductances [2].

No wonder that alternative topologies of converters, such as the multilevel converters [3] or hybrid converters [4] have excited a vivid interest of researchers. Multilevel converters are particularly attractive in high power applications where power converters with high voltage, high current, and considerably reduced harmonics are required. On the other side, The principle of operation of the hybrid converter is different where the primary converter produces rectangular current pulses and provides most of the energy to the load and the secondary converter supplies the harmonic power required for making the load current waveforms sinusoidal. Despite the advantages of these topologies, they are costly and their structure and control are complicated.

Recently, the matrix converter was proposed as a final solution to these problems [5]. The matrix converter uses bi-directional fully controlled switches for direct conversion from ac to ac. It is a singlestage converter that requires only nine switches for three-phase to three-phase conversion. In respect to advantages compared with a traditional converter, it has full four-quadrant operation, input power factor control, and no dc-link. However, because of no energy storage, the power at the input can also be seen at the output. Grid disturbances will affect the output immediately, and it is important to select a proper protection strategy [6].

To overcome the problems associated with different converter topologies, This paper proposes a novel intermediate line regulator suitable for use as a current source converter for ac power applications. First of all, the power circuit topology of the proposed converter is presented. Next, the principle of operation and detailed description of the control scheme are illustrated. Finally, simulation and experimental work are carried out.

\section{POWER CIRCUIT TOPOLOGY}

\subsection{Single Phase Arrangement}

The proposed regulator is formed by several discrete components in series and parallel connection as shown in Fig. 1.
The input inductor $\mathrm{L}_{\mathrm{i}}$ and output inductor $\mathrm{L}_{0}$ are in the range of $0.5-0.75 \mathrm{H}$, while the input and output resistors are equal at $18 \mathrm{~K} \Omega$ approximately. These values are derived from the regulated line filter proposed in [7] with some modifications and enhancements to be suitable for the application as a current source converter. The combination of intermediate inductors, $L_{1}, L_{2}$ and $L_{3}$, constitutes the controlled inductor $\mathrm{L}_{\mathrm{C}}$. Likewise, the output capacitors, $\mathrm{C}_{1}$ and $\mathrm{C}_{2}$, constitutes the controlled capacitor $C$. The values of $L_{1}, L_{2}, L_{3}, C_{1}$ and $C_{2}$ are susceptible to change according to the output current required. The two switches $S_{1}$ and $S_{2}$ are bidirectional switches of the MOSFET type and its gating signal is derived from the control circuit.

On the output terminals a voltage transducer and current transducer are used to extract the voltage and current signals. These signals are then provided to the control circuit to be processed giving the desired control action.

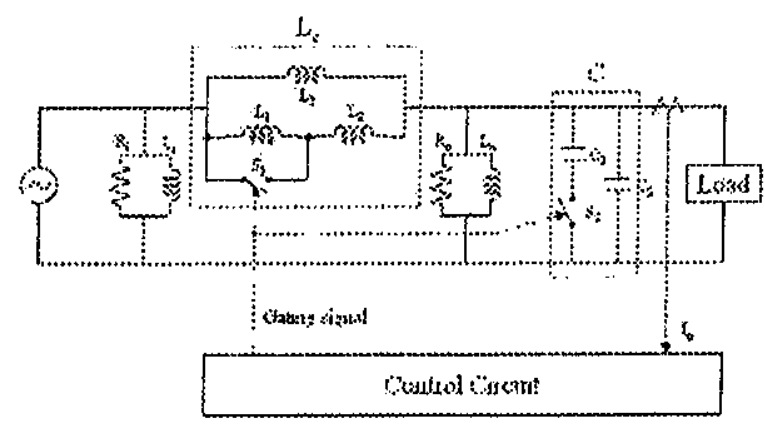

Fig. 1 Power circuit design of the proposed regulator

\subsection{Three Phase Arrangement}

A three-phase regulator is normally used in high power applications. The circuit diagram of the proposed regulator in its three-phase structure is shown in Figure 2. It is composed of a three singlephase regulators connected to a three-phase supply as an input and a three-phase load on its output terminals.

It is evident that using the proposed three-phase regulator as a CSC is more efficient than semiconductor switches instead of twelve semiconductor switches. Another advantage of the proposed three-phase regulator is the simplicity in building its control scheme. This simplicity is arising from two reasons. First one is that the feedback signal is extracted from only one phase without any special processing as in conventional CSCs [8]. Second reason is a result of using the same gating signal for all semiconductor switches. 


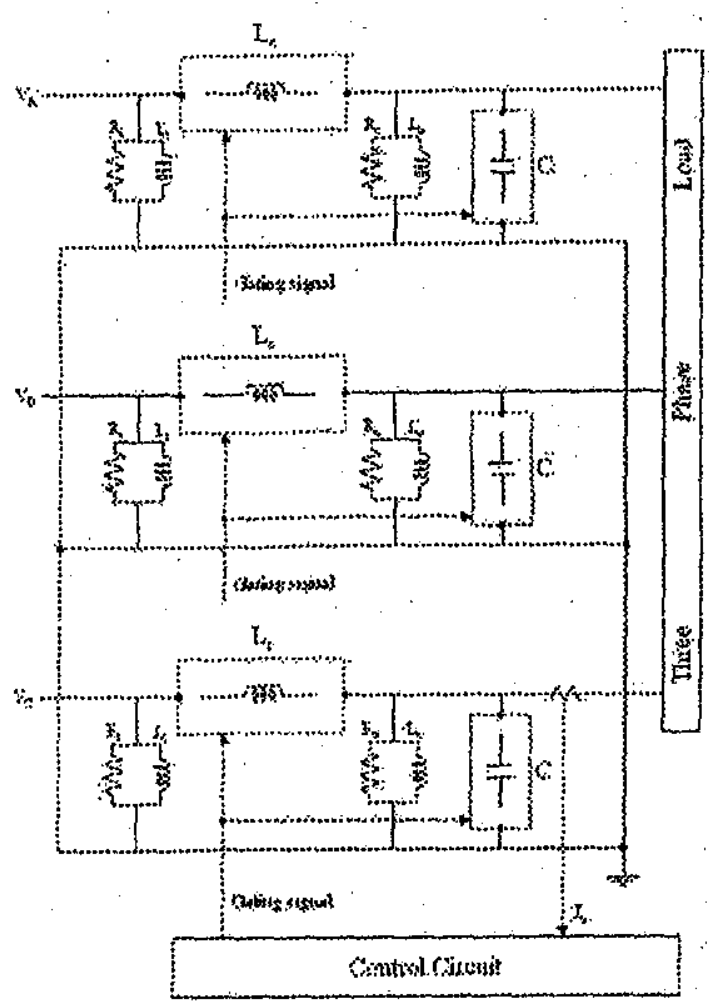

Fig. 2 Three-phase arrangement of the proposed regulator

\section{PRINCIPLE OF OPERATION}

The two-port network concept is used to analyze the operation of the proposed regulator as a current source converter. The ratio of interest in this study is the input voltage $\left(V_{i}\right)$ divided by the output current $\left(I_{0}\right)$ when the input current $\left(I_{i}\right)$ is equal to zero, which represents the open-circuit reverse-transfer impedance $Z_{12} \cdot[9]$ as given from the following equation:

$$
Z_{12}=\left.\frac{V_{i}}{I_{0}}\right|_{l_{1}=0}
$$

For the sake of simplicity the input and output parallel resistors, $R_{i}$ and $R_{0}$, have been neglected without significant effect on the final result because their values are large compared to the parallel inductors. The relation between the output current $I_{0}$, the capacitor current $I_{0}$, the intermediate inductor current $I_{L_{c}}$, and the output inductor current $I_{L o}$ is defined in S-domain as follow:

$$
\begin{aligned}
& I_{0}(s)=I_{c}(s)+I_{L_{c}}(s)+I_{L_{0}}(s) \\
& \text { Where: } \quad I_{c}(s)=s C V_{o}(s) \\
& I_{L_{c}}(s)=\frac{V_{0}(s)-V_{i}(s)}{s L_{c}} \\
& I_{L_{0}}(s)=\frac{V_{0}(s)}{s L_{0}}
\end{aligned}
$$

On the other hand, when the input current $I_{i}$ is equal to zero the current $I_{L c}$ will be equal to the input inductor current $\mathrm{I}_{\mathrm{Li}}$ as follows:

$$
I_{L c}(s)=I_{L i}(s)=\frac{V_{i}(s)}{s L_{i}}
$$

Solving equations (4) and (6) for the output voltage yields:

$$
V_{0}(s)=V_{i}(s)\left[\frac{L_{c}}{L_{i}}+1\right]
$$

Substituting equations (2) and (7) into (1) gives $Z_{12}$ in the following form:

$$
Z_{12}=\frac{V_{i}(s)}{I_{0}(s)}=\frac{s L_{i} L_{0}}{\left(L_{c}+L_{i}\right) C L_{0} s^{2}+L_{c}+L_{i}+L_{0}}
$$

It can be assumed that $\mathrm{L}_{\mathrm{i}}=\mathrm{L}_{\mathrm{o}}=\mathrm{L}$ and $\mathrm{L}_{\mathrm{c}}$ is much smaller than $\mathrm{L}_{\mathrm{j}}$ or $\mathrm{L}_{0}$. Then, equation (8) can be rewritten as follows:

$$
\frac{V_{i}(s)}{I_{0}(s)}=\frac{s L}{s^{2} C L+2}
$$

From equation (9), it can be concluded that the output current is in direct proportion with only the capacitance $C$ where $L$ is constant. Thus, this current can be kept constant by the appropriate control of the capacitance value.

\section{CONTROL SCHEME}

In the proposed regulator, two different control methods are compared to choose the superior one. These methods are PI control and fuzzy logic based control.

\subsection{PI Control}

The PI controller is common in control systems. In PI controller, the integral of the exror as well as the error itself is used for control. This type of controller is a first order system and its transfer function is given as follows:

$$
\mathrm{G}(\mathrm{s})=\mathrm{K}_{\mathrm{p}}+\frac{\mathrm{K}_{\mathrm{I}}}{\mathrm{s}}
$$

Where, $\mathrm{K}_{\mathrm{P}}$ and $\mathrm{K}_{\mathrm{I}}$ are the controller parameters. The objective of using PI controller is to combine transient response characteristics of proportional control with the zero steady state error characteristic of integral control. Proper controller design requires tuning the parameters $\mathrm{K}_{\mathrm{P}}$ and $\mathrm{K}_{\mathrm{I}}$ to give the desired control action.

\subsection{Fuzzy Logic Based Control}

The design of fuzzy logic based control (FLC) used in this work is shown in Figure 3.

The total fuzzy inference system is a mechanism that relates the inputs to a specific output or set of outputs. First, the inputs are categorized linguistically (fuzzification), then the linguistic inputs are related to outputs through fuzzy rules and, finally, all the different outputs are combined to produce a single output (defuzzification). 


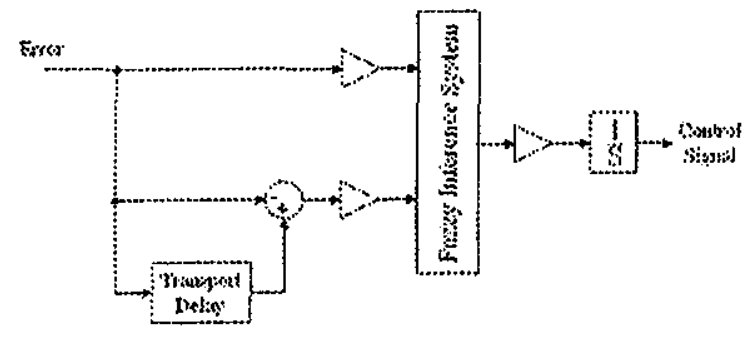

Fig. 3 Fuzzy controller design

The main purpose of the fuzzification layer is to take the inputs and determine the degree to which they belong to each of the appropriate fuzzy sets via membership functions. Fuzzification of the input results in a fuzzy vector where each component of this vector represents the degree of membership of the linguistic variables into a specific fuzzy variable's category. The number of components of the fuzzy vector is equal to the number of fuzzy variables used to categorize specific linguistic variables. Then, the fuzzy inference engine uses the fuzzy vectors to evaluate the fuzzy rules and produce an output for each rule. There are three different shapes of membership functions, triangular, trapezoidal and Gaussian. In this study the Gaussian shape are used for the input membership functions with three linguistic variables as shown in Figure 4. Gaussian membership function has the advantage of being smooth and nonzero at all points.

The fuzzy inference engine often has multiple rules, each with possibly a different output. Deffuzzification refers to the method employed to combine these many outputs into a single output. There are a number of methods used for defuzzification. The most common defuzzification method is the centroid calculation, which returns the center of area under the curve, and this method is the one employed in this study.

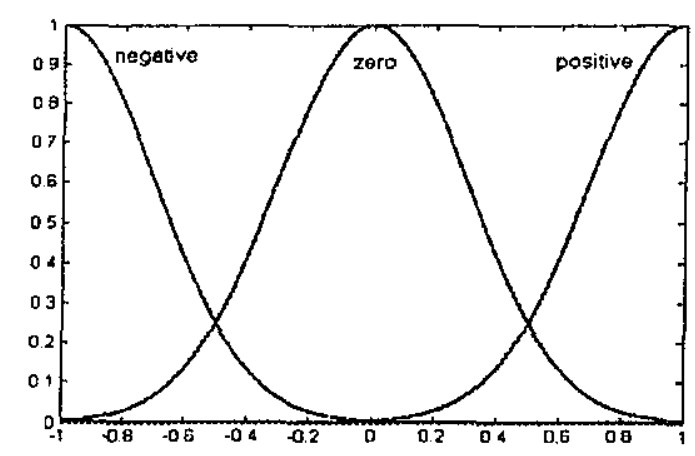

Fig. 4 Input membership functions

\section{SLMULATION RESULTS}

The performance of the proposed regulator as a current source converter is assessed by a computer simulation that uses MATLAB/SIMULINK. Different simulation tasks are carried out to examine the performance of the converter. The first task is dedicated to the evaluation of the converter performance to follow the current reference. The second task is devoted to assess the converter capability to supply constant current under different loading conditions.

\subsection{Simulation Results Using PI Control}

The dynamic performance of the converter for a step change in the current reference is presented in Figures 5 and 6 . Figure 5 presents a step-up change in the reference from $0.09 \mathrm{~A}$ to $0.13 \mathrm{~A}$ and Figure 6 presents a step-down change from $0.13 \mathrm{~A}$ to $0.09 \mathrm{~A}$. The output waveforms and RMS values are shown in parts (a), (b), (c), and (d) respectively while part (e) shows the error signal. It is observed that the output current follows up the current reference with good transient characteristics. Figures 7 and 8 show the output waveforms and error signal under load step changes. The load resistance is changed from 11.1 to $23 \Omega$ in Figure 7 and from 23 to $11.1 \Omega$ in Figure 8 . These results reveal that the proposed converter has a fast response and accurate performance in supplying constant current under different loading conditions. In addition, the output waveforms of current and voltage are sinusoidal.

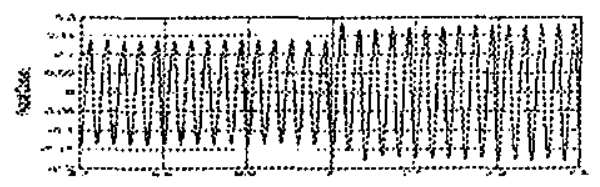

(b)

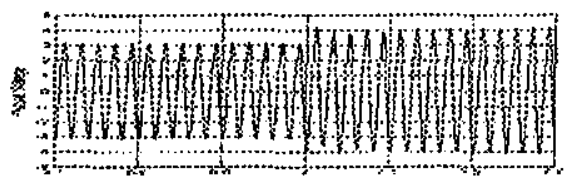

(c)

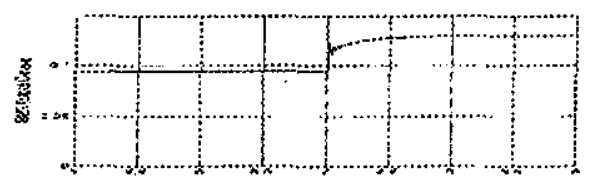

(d)

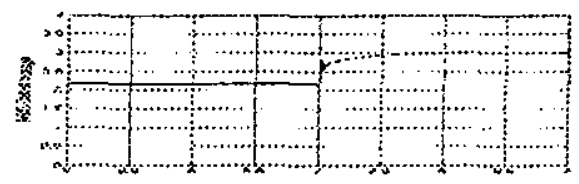

(e)

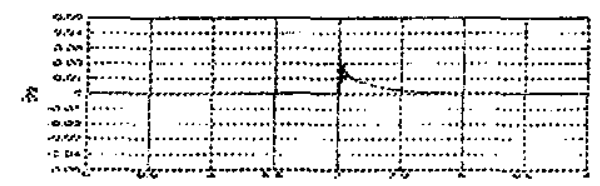

Fig. 5 Simulation results for a step-up change in the current reference from $0.09 \mathrm{~A}$ to $0.13 \mathrm{~A}$ using PI control, (a) output current. (b) output voltage.

(c) RMS output current. (d) RMS output voltage.

(e) error signal. 
(a)

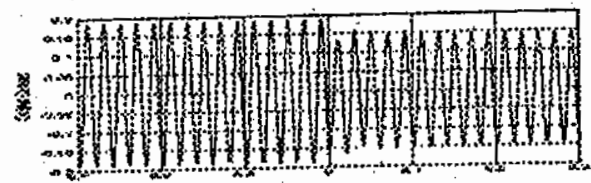

(b)

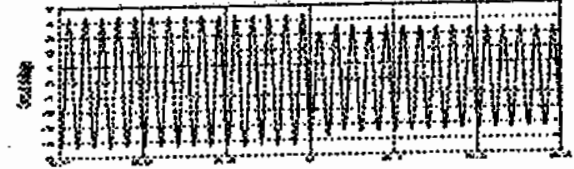

(c)

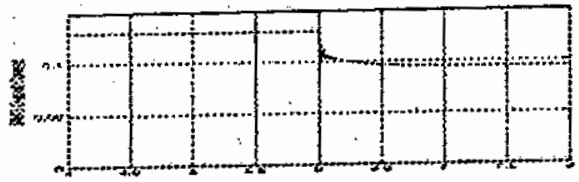

(d)

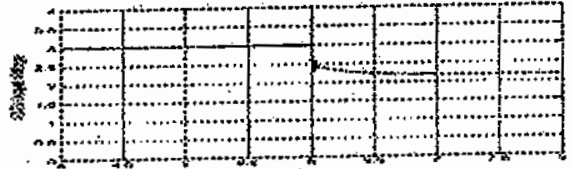

(e)

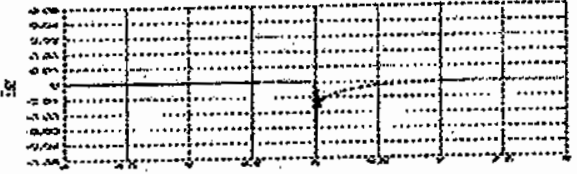

Fig. 6 Simulation results for a step-down change in the current reference from $0.13 \mathrm{~A}$ to $0.09 \mathrm{~A}$ using PI control. (a) output current. (b) output voltage.

(c) RMS output current. (d) RMS output voltage. (e) error signal.

(a)

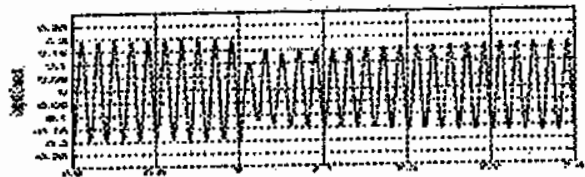

(b)

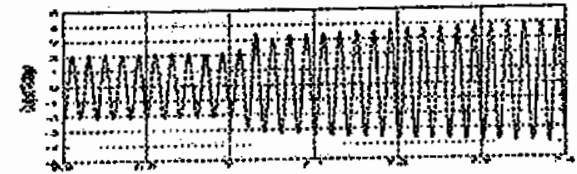

(c)

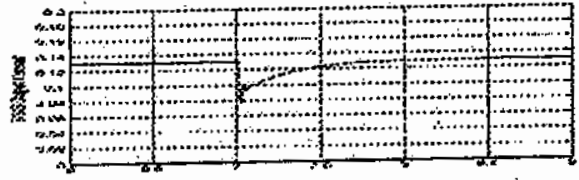

(d)

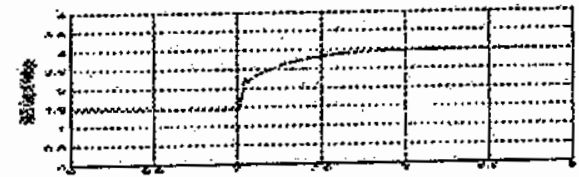

(e)

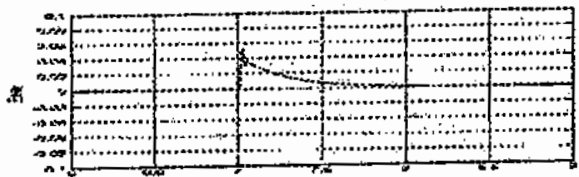

Fig. 7 Simulation results for a step-up change in the load resistance from $11.1 \Omega$ to $23 \Omega$ using PI control. (a) output current. (b) output voltage. (c) RMS output current. (d) RMS output voltage. (e) error signal. (a)

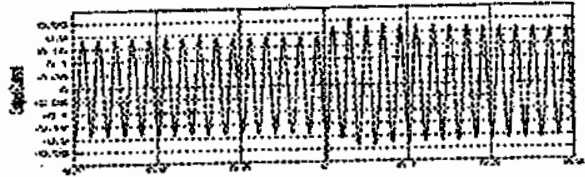

(b)

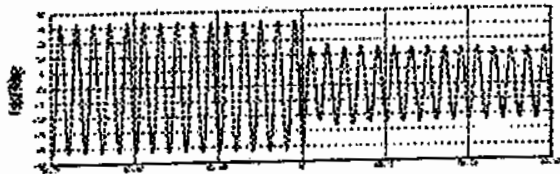

(c)

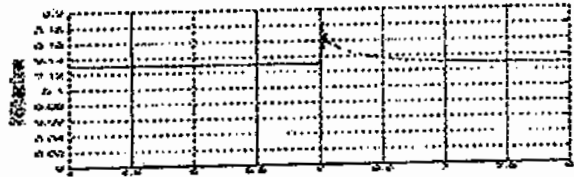

(d)

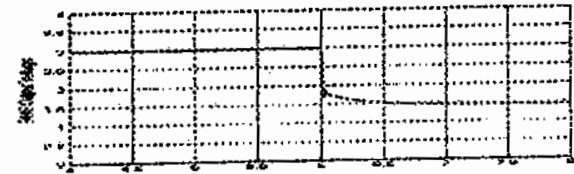

(e)

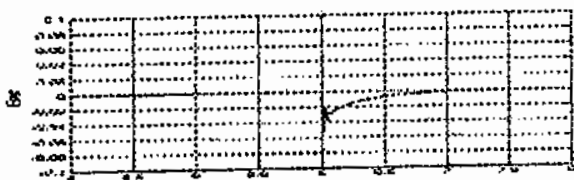

Fig. 8 Simulation results for a step-down change in the load resistance from $23 \Omega$ to $11.1 \Omega$ using PI control. (a) output current. (b) output voltage.

(c) RMS output current. (d) RMS output voltage. (e) error signal.

\subsection{Simulation Results Using FLC}

This section studies the converter performance using fuzzy logic based control. The output waveforms and error signals of the transient response for a step change in load and reference respectively are depicted in Figures 9 and 10. The values of load resistance and current reference in different cases are the same values as that used with PI control. It is clear that the transient stage in different cases is less than that obtained using PI control.

\subsection{Simulation Results for the Three Phase Arrangement}

Figure (11) depicts the three phase voltages, currents, RMS values, and error signals for a step change in the reference. it is evident that the output current tracks the reference and accordingly the output voltage also changes. On the other side, Figure 12 shows the same waveforms but for a step change in load. In the last case the response is different where the output current remains constant with load change and the only change occurs in the output voltage. 
(a)

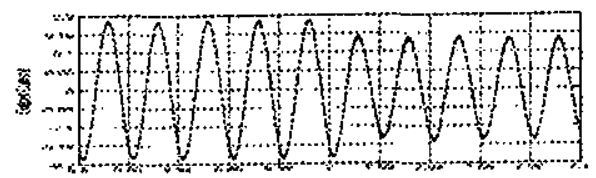

(b)

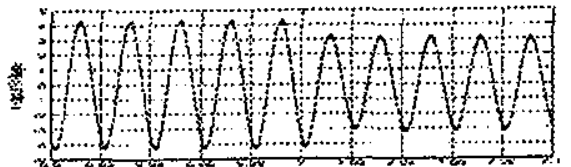

(c)

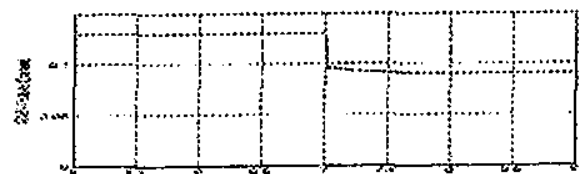

(d)

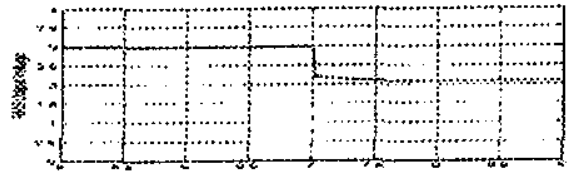

(e)

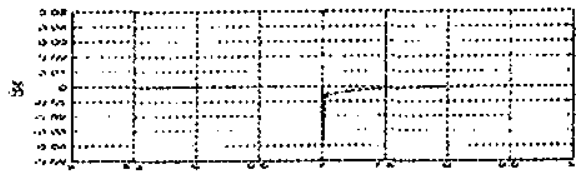

Fig. 9 Simulation results for a step change in the current reference from $0.13 \mathrm{~A}$ to $0.09 \mathrm{~A}$ using FL control. (a) output current. (b) output voltage.

(c) RMS output current. (d) RMS output voltage. (e) error signal.

(a)

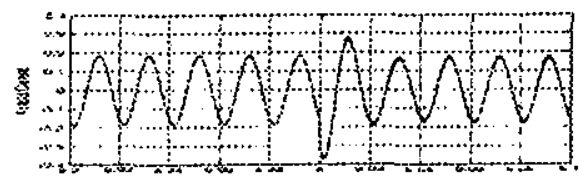

(b)

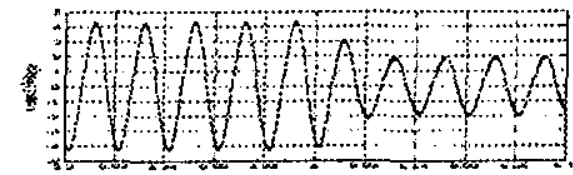

(c)

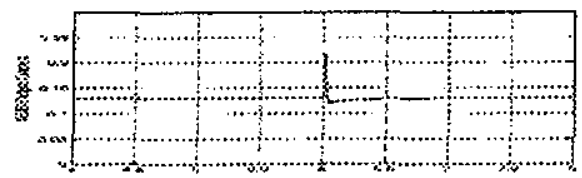

(d)

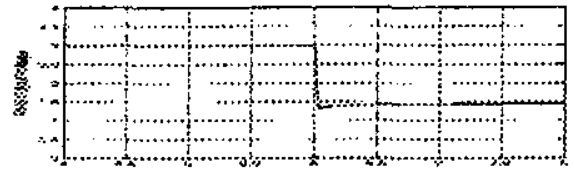

(e)

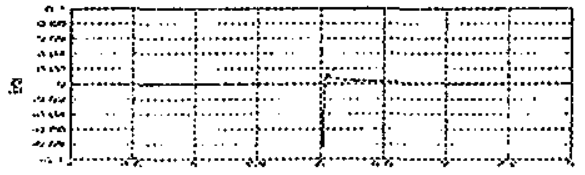

Fig. 10 Simulation results for a step change in the load resistance from $23 \Omega$ to $11.1 \Omega$ using FL control. (a) output current. (b) output voltage. (c) RMS output current. (d) RMS output voltage. (e) error signal. (a)

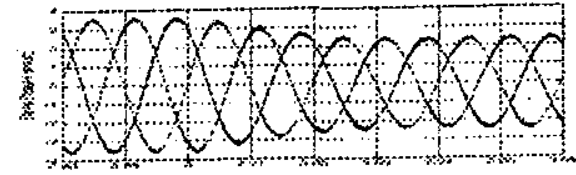

(b)

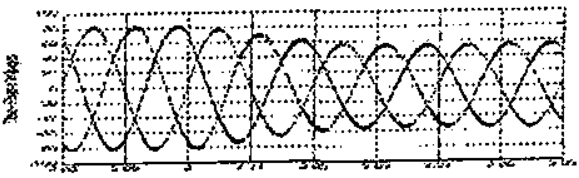

(c)

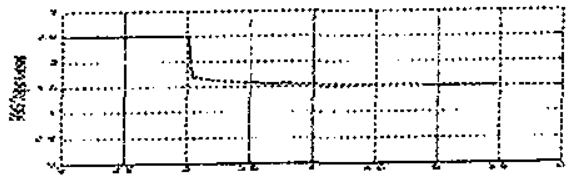

(d)

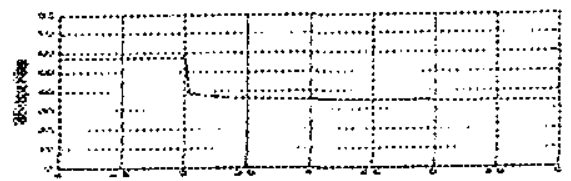

(e)

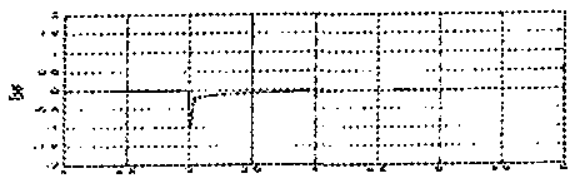

Fig. 11 Simulation results of the 3-phase arrangement for a step-down change in the current reference from $2.5 \mathrm{~A}$ to $1.5 \mathrm{~A}$. (a) output current.

(b) output voltage. (c) RMS output current.

(d) RMS output voltage. (e) error.

(a)

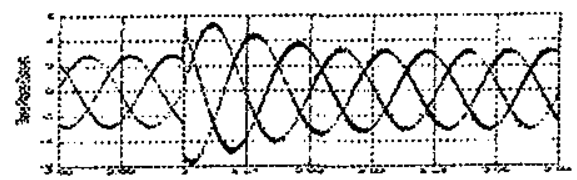

(b)

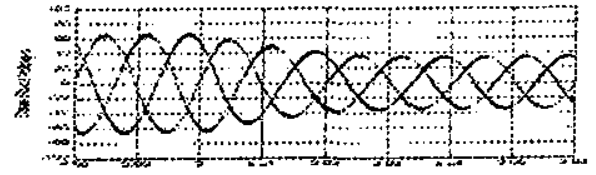

(c)

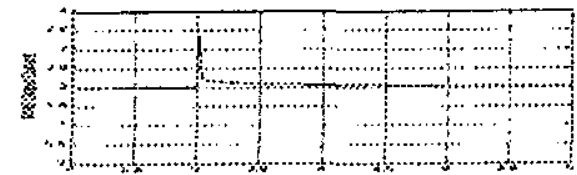

(d)

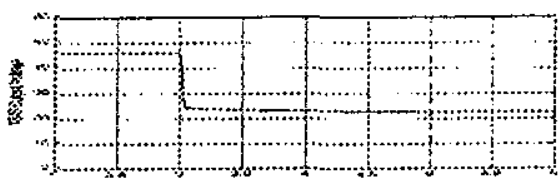

(e)

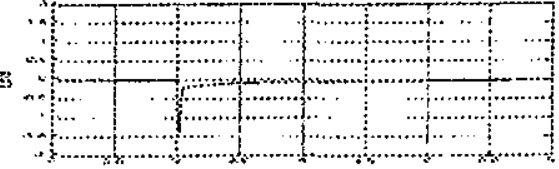

Fig. 12 Simulation results of the 3-phase arrangement for a step-down change in load resistance from $23 \Omega$ to $11.1 \Omega$. (a) output current.

(b) output voltage. (c) RMS output current.

(d) RMS output voltage. (e) error. 


\section{EXPERIMENTAL RESULTS}

In order to validate the effectiveness of the proposed comverter configuration and to check out the simulation results, a laboratory prototype based on DSP has been designed and constructed, as represented in Figure 13. The experimental results are carried out for the single phase arrangement only due to existent laboratory restraints. It has to be pointed out that a relatively small input voltage is used to ensure an unsaturated operation of the intermediate inductors, $L_{1}, L_{2}$ and $L_{3}$. This can be modified to a large scale if large inductors are available. The values of inductors $L_{1}, L_{2}$ and $L_{3}$ are $75 \mathrm{mH}, 30 \mathrm{mH}$ and $30 \mathrm{mH}$ respectively, and their wiring resistance measured $1 \Omega$. The fixed capacitor on the output terminals is set to $95 \mu \mathrm{F}$ while the switched capacitor is $247 \mu \mathrm{F}$. A variable resistive load is used to examine the converter performance with load change. In the proposed converter, the digital signal processor type used is TMS320 C31. First, the controller and the PWM blocks are designed in MATLAB/SIMULINK. Afterwards, the interface between MATLAB/ SIMULINK and digital signal processor. allows the control algorithm to be run on the hardware. One analog-to-digital converter is used for the sensed load current. An optoisolated interface board is also designed in order to isolate between the entire DSP and the power circuit. The gating signal are then applied to the power switches. the application of DSP-based control offers many features that are not found in analog control such as programmability, flexibility, and insensitivity to aging and environmental variations.

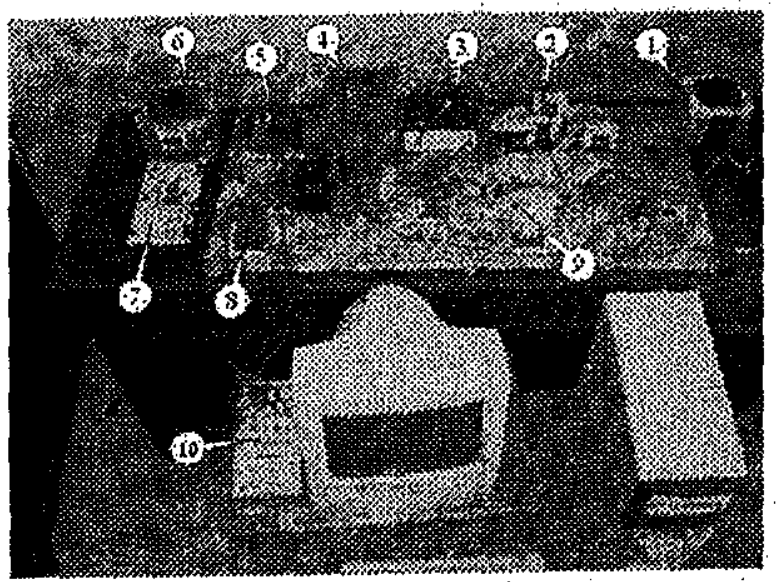

Fig. 13 Experimental setup of the proposed converter
1) Input inductor.
6) Output iriductor.
2) Intermediate inductors.
7) \pm 15 V DC source.
3) Output capacitors.
8) Optoisolated board.
4) Variable resistive load.
9) MOSFET switch.
5) Current transducers.
10) I/O interface:

Figure 14 and Figure 15 show transient response waveforms of the converter to step changes in the current reference. Parts $(a, b)$ show the output current and voltage respectively while parts $(c, d)$ show the corresponding RMS values. As depicted, the converter output current follows the reference and consequently, the output voltage also changes. Part (e) shows the error signal between the reference and RMS output current. This error returns to zero after transient stage.

Figure 16 and Figure 17 show experimental results of the proposed converter when subjected to load changes. Figure 16 shows the response to a load change from 11.1 to $23 \Omega$, and Figure 17 the response to a load step from 23 to $11.1 \Omega$. These results illustrate how the proposed converter effectively supply the same current under such load impacts. Traces depicted are output current and voltage, RMS values of output current and voltage, and error signal respectively.

Figure 18 shows spectral component of the output current for all possible combinations of reference and load resistance. It can be observed that the proposed converter always has sinusoidal output current waveforms with drastically reduced contents of loworder harmonics.

(a)
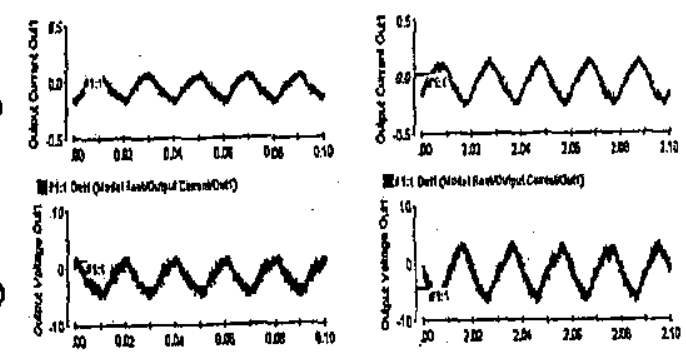

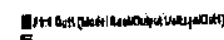

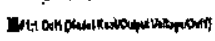

(c)

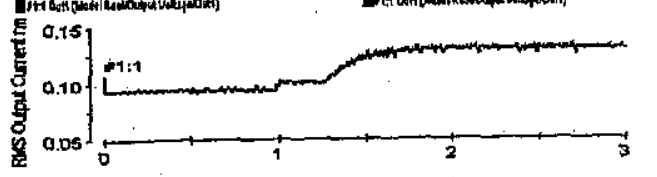

(d)

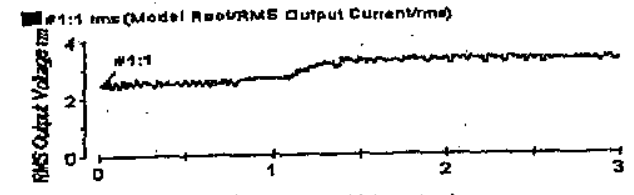

(e)

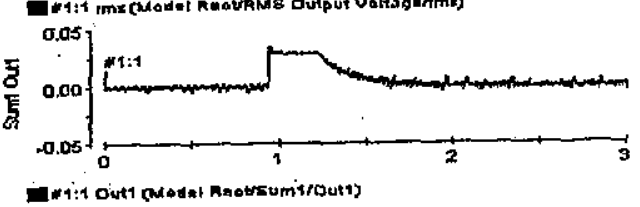

Fig. 14 Experimental results for a step-up change in the current reference from $0.09 \mathrm{~A}$ to $0.13 \mathrm{~A}$

(a) output current. (b) output voltage. (c) RMS output current. (d) RMS output voltage. (e) error signal. 
(a)
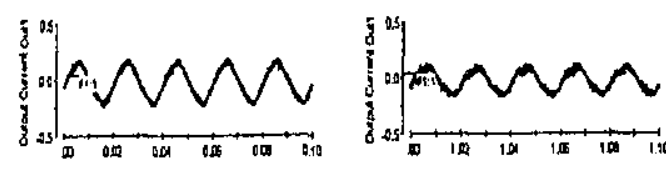

(b)

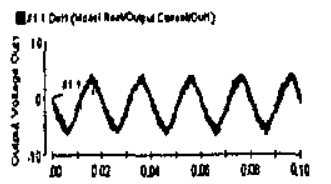

(c)

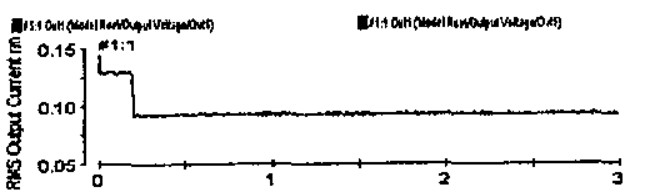

(d)

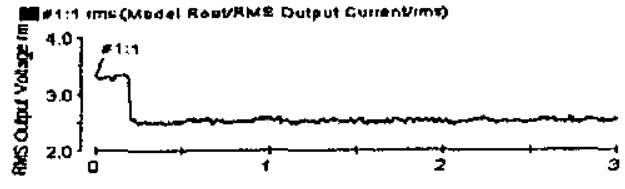

(e)

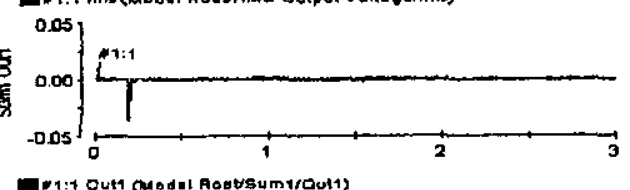

Fig. 15 Experimental results for a step-down change in the current reference from $0.13 \mathrm{~A}$ to $0.09 \mathrm{~A}$

(a) output current. (b) output voltage. (c) RMS output current. (d) RMS output voltage. (e) error signal.

(a)

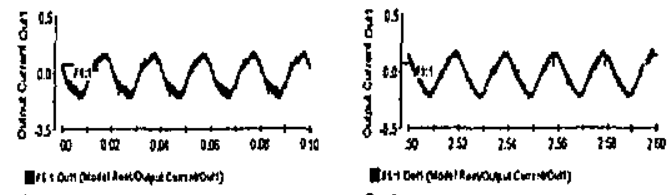

(b)

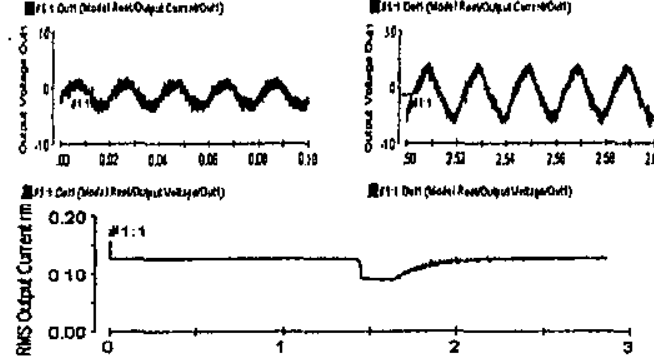

(d)

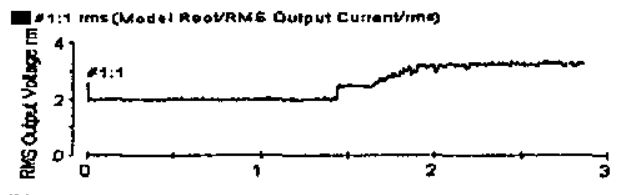

(e)

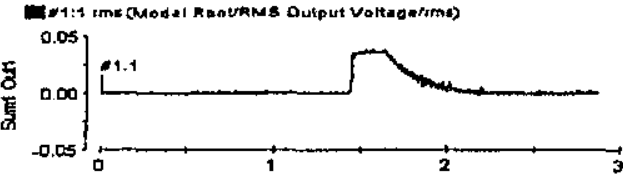

Fig. 16 Experimental results for a step-up change in the load resistance from $11.1 \Omega$ to $23 \Omega$. (a) output current. (b) output voltage. (c) RMS output current.

(d) RMS output voltage. (e) error signal. (a)
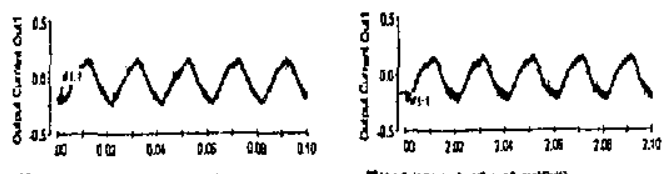

(b)
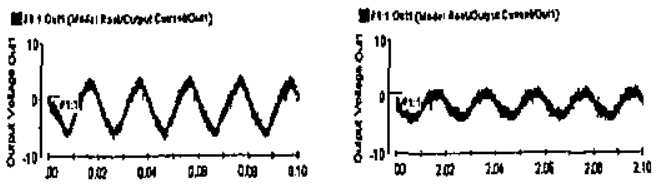

(c)

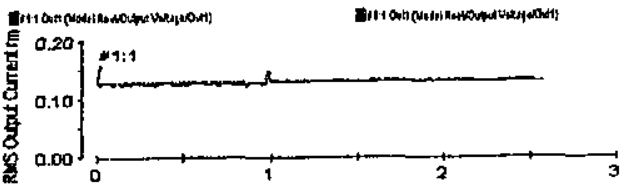

(d)

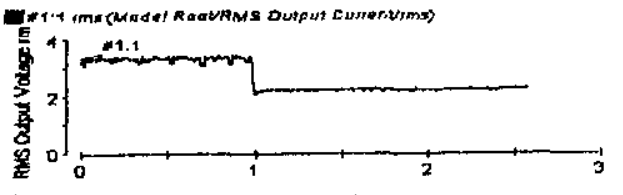

(e)

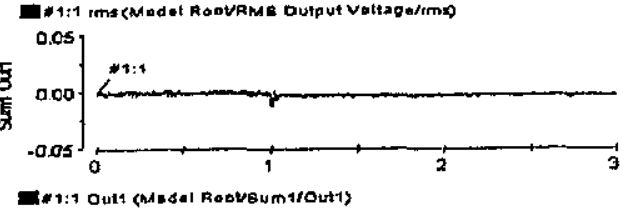

Fig. 17 Experimental results for a step-down change in the load resistance from $23 \Omega$ to $11.1 \Omega$. (a) output current. (b) output voltage. (c) RMS output current.

(d) RMS output voltage. (e) error signal.

(a)

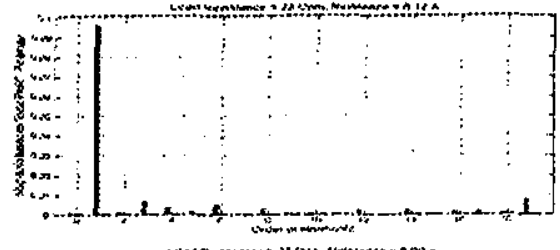

(b)

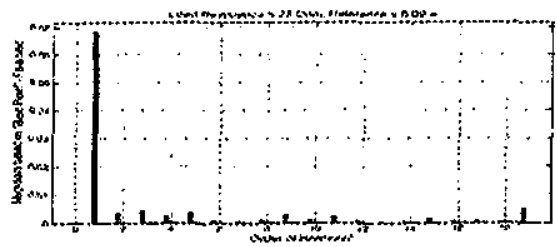

(c)

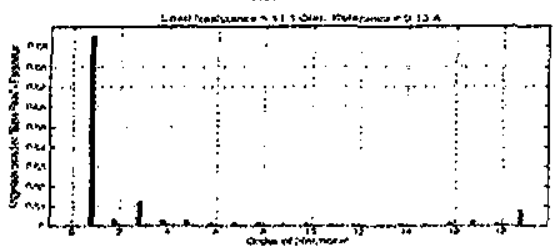

Fig. 18 Spectral component of the output current for different combinations of the reference and load resistance, (a) $R_{\mathrm{L}}=23 \Omega$ and $I_{\mathrm{Ref}}=0.13 \mathrm{~A}$

(b) $\mathrm{R}_{\mathrm{L}}=23 \Omega$ and $\mathrm{I}_{\mathrm{Ref}}=0.09 \mathrm{~A}$.

(c) $\mathrm{R}_{\mathrm{L}}=11.1 \Omega$ and $\mathrm{I}_{\mathrm{Ref}}=0.13 \mathrm{~A}$. 


\section{CONCLUSTON}

A novel intermediate line regulator suitable for use as a current source converter was proposed in the work of this paper. The power circuit topology and control scheme of the proposed regulator was discussed. The design of the proposed regulator exhibited the advantage of using less number of semiconductor devices and consequently, reducing switching losses. The analysis of the proposed regulator as a current source converter showed that the output current is in direct proportion with the output capacitance. Thus, this current can be kept constant by the appropriate control of the capacitance value. The proposed converter was simulated using MATLAB/ SIMULINK software and the simulation results showed that the proposed converter had succeeded in supplying constant output current with high accuracy under different loading conditions: The simulation results also showed that the proposed converter has good transient characteristics in tracking the current reference. A comparison between using PI control and fuzzy logic based control was made and the results showed that the transient response is faster in case of fuzzy logic based control. The simulation results proved that the proposed converter is applicable not only for singlephase systems but also for three-phase systems which makes it suitable for use in AC drives. Experimental work was built using digital signal processor and the results validated the converter effectiveness in keeping the output current constant with load change as well as following the current reference. The experimental results showed a good agreement with simulation results.

\section{REFERENCES}

[1] J. R. Espinoza and Others, "Selective Harmonic Elimination and Current/Voltage Control in Current/Voltage-Source Topologies: A Unified Approach", IEEE Transactions on Industrial Electronics, Vol.48, No.1, February 2001, pp.7181.
[2] Y. Neba, "A Simple Method for Suppression of Resonance Oscillation in PWM Current Source Converter", IEEE Transactions on Power Electronics, Vol.20, No.1, Janiary 2005, pp.132139.

[3] J. S. Lai and F. Z. Peng, "Multilevel ConvertersA New Breed of Power Converters", IEEE Transactions on Industry Applications, Vol.32, No.3, May / June 1996, pp.509-517.

[4] S. Fukuda, Y. Kubo, and M. Kitano, "Introduction of a Hybrid Multi-Converter System And Its Control Strategy", Proceedings of the Power Conversion Conference, PCC 2002, Osaka, Japan, April 2-5, pp.372-377.

[5] D. G. Holmes and T. A. Lipo, "Implementation of a Controlled Rectifier Using AC-AC Matrix Converter Theory", IEEE Transactions on Power Electronics, Vol.7, No.1, January 1992, pp.240250.

[6] P. Nielsen, F. Blaabjerg, and J. K. Pedersen, "New Protection Issues of a Matrix Converter: Designi Considerations for Adjustable-Speed Drives", IEEE Tränsactions on Industry Applications, Vol.35, No.5, September/October 1999, pp.1150-1161.

[7] M. E. Abdel-Karim, "A Regulated Line Filter for Low Power Applications", Alexandria Engineering Journal, Vol.40, No.6, 2001, pp.835-843.

[8] A. B. Rey, S. de Pablo, and J. M. Ruiz, "Decoupled current source vector control of a 3phase grid-connected inverter using a novel vector utility observer for synchronization", Proceedings of the International Conference on Power Electronics, Machines and Drives, PEMD 2004, March 31 - April 2, pp.609-614.

[9] R. L. Boylestad, Introductory Circuit Analysis, Seventh Edition, Macmillan Publishing Company, New York, 1994. 